\title{
Integrating CALL and Genre Theory: A proposal to increase students' literacy
}

\author{
MARÍA MARTÍNEZ LIROLA AND MARÍA TABUENCA CUEVAS \\ University of Alicante Departamento de Filología Inglesa Campus de San Vicente del \\ Raspeig, Ap.99. E-03080 (Alicante) Spain \\ (email: \{maria.lirola,maria.tabuenca\}@ua.es)
}

\begin{abstract}
The use of computer programs that can be used to correct and assess students' written work in the EFL classroom has become more commonplace within the last decade. This paper discusses the role of CALL in the process of data collection, standardisation of assessment criteria and compilation of the number of errors in the areas of grammar learning and its application to L2 writing. Students benefited from the correction process and showed increased grammatical awareness through the corrected feedback. However, the analysis of the results after the first correction phase demonstrated that the students had improved less than expected. For this reason, in the second year, Genre Theory was adopted as a theoretical framework so that students would become aware of the relationship between the structure and shape of texts in order to be effective in a particular context, and to achieve the goals of a particular culture. As proponents of the genre approach, we argue that making the genres explicit and showing how to write them will help students to be aware of how knowledge is structured in different written genres. A careful selection of text types was made at the beginning of the year so that improvement in the students' writing not only depended on the CALL system being used, but also on the different genres or text types used as class material. In this study, we intend to demonstrate that the combination of new technologies in the classroom and Genre Theory helped students to increase their writing competency. Our research highlights the relationship between literacy, new technologies, and effective writing with an emphasis on the educational application.
\end{abstract}

Keywords: writing skills, error correction, Genre Theory, CALL, text types, textuality.

\section{Introduction}

The study reported in this paper is an overview of a two year study in which the computer program Markin developed by Martin Holmes (1996-2002) was used to correct a corpus of essays written in English by Spanish students on the English Language IV course at the University of Alicante. Eighty essays were analysed in total: forty in the first year and forty in the second year. 
The first year of the study concentrated on error analysis whereby the program was used to classify and monitor the frequency of the types of errors corrected. The feedback mechanism was used to help students become aware of their errors and so become more autonomous learners. The analysis of the results after the first forty essays demonstrated that the improvement in students' writing skills after the first year was less than expected. For this reason, nothing was published about the first year of the study.

After this unexpected result in the use of CALL as an instrument for error correction in the classroom, we became interested in the relationship between grammar and meaning and grammar and context. It was clear that the use of CALL had to be combined with an adequate theoretical framework to reap maximum results. As de Sylva and Burns (1999: 34) point out, if we see language as functionally related to its context of use, "grammar is seen as determined by the kinds of discourses and texts that people need to produce for different purposes in different social contexts." For this reason, in the second year, the Genre Theory was adopted as a theoretical framework so that students would become aware of the relationship between the structure and shape of texts in order to be effective in a particular context and to achieve the goals of a particular culture. In this article we intend to demonstrate that the use of the Genre Theory helps students to increase their level of literacy. Literacy can be defined as the ability to function effectively within a given set or sets of discourse practices embedded in their social and cultural contexts.

Neither the computer program Markin nor computers in general are pedagogical tools in themselves; they have the potential to acquire pedagogical meaning when the teacher adapts the use of the technology and combines it with his/her own methodology of teaching and learning a language.

Previous studies (Fernández Carballo-Calero, 2001; Hogan-Brun \& Whittle, 1998) concentrated on the analysis of the didactic applications of the software and multimedia tools but they did not combine these applications with Genre Theory in the classroom, i.e., they did not pay special attention to the text types used in their studies nor to the context in which those texts were produced. In general, the other studies we have reviewed paid attention to the importance of learning to use software, to the software's shortcomings and to the new roles of teachers and learners in the teaching / learning process. There are also studies that just use the software to correct specific morphological errors (Feng, Ogata \& Yano, 2000), which is quite different from the study presented in this paper, as Markin is used to correct different types of grammatical errors and to monitor textuality.

As we searched for previous studies in the field (cf. Díez, Halbach \& Rivas, 2002; Cabellos, Díaz \& Halbach, 2002) we realized that few had been done on methodologies for Spanish students studying English as their L2 to improve their writing skills. For this reason, we will highlight the relationship between literacy, Genre Theory, and effective writing with an applied educational emphasis using the genre approach developed from the work of Michael Halliday. In his Introduction to Functional Grammar, Halliday declares that the educational application of Systemic Functional Linguistics (hereafter SFL) is " $[\ldots]$ probably the broadest range of its applications; it includes experience in initial literacy, children's writing, language in secondary education, classroom discourse analysis, teaching of foreign languages, analysis of textbooks, error analysis, teaching of literature and teacher education" (Halliday, 1994:xxx). 
This theory argues that human beings have developed different ways of using language depending on the things they want to accomplish in a particular culture. As Martin (1997:13) states: "As a level of context, genre represents the system of staged goal oriented social processes through which social subjects in a given culture live their lives".

In general, the teachers who had taught this course before focussed almost exclusively on language-related problems at the sentence level and gave minimal attention to discourse-related aspects of writing; that is why the error correction exercises had always been at the sentence level. In addition, students were simply required to repeat the structures without being aware of the sense and real meaning of them. The use of drills eliminates the creative component of a language: errors are avoided because the use of language is very limited. Thus, the students were accustomed to immediate retrospection concerning error correction but were not able to apply the correct grammatical structures in their own essays. Genre Theory highlights the fact that in teaching writing, teachers need to pay attention not only to the processes of composing texts but also to the nature of texts that students write (Hammond \& Derewianka, 2001:187). For this reason, different contexts and language purposes are associated with different genres or text types. Each genre is characterised by the use of different grammatical structures and by having a different social purpose.

Our main research question was how to respond to students' work in ways that help their language progress. Krashen (1985:2) makes clear that second languages are acquired "by understanding messages, or by receiving "comprehensible input". The role of instruction has been questioned in second language acquisition since Krashen (1985) argued that instruction and conscious knowledge of linguistic rules are irrelevant for acquisition. Krashen's ideas about the importance of using language for communication led us to another research question concerning the validity of using complete texts in the classroom to improve students' writing skills.

\section{The project and research method}

In English Language IV the correction procedure for correcting written work had traditionally focused on cohesive devices within the sentence (Halliday \& Hasan 1976:78). Our aim was to increase this cohesion by correcting the grammatical structures in the students' writing. Needless to say, native Spanish students had many problems writing in English as L2. The main difficulties were multiple grammar errors, a general misuse of conjunctions and a lack of organization in the development of ideas. There were also ambiguities, problems with reference and abuse of repetition. In certain cases, the choice of vocabulary and grammatical patterns was not appropriate for the register or text type and complex grammatical devices for emphasis were hardly ever used. It is necessary at this point to talk about the kind of error correction practice that the students had in the English Language IV course. Problem areas in grammar were identified at the beginning of each year by using a placement test based on the book Advanced Grammar in Use by Hewings (2005). Error correction classes were limited to only one hour a week per group. This severely limited the methodology of the error correction classes and obliged the teachers to use drilling exercises and lectures to try to get the message across. The students were then expected to apply this knowledge to their writing. 
One of the objectives of the study, as previously mentioned, was to assess the application of the knowledge gained in the error correction classes through the assessment not only of grammar tests but also of the students' writing skills. Since grammar is a resource used for making and exchanging meaning (Halliday, 1978), it is very important for students to be aware that their errors have a clear effect in communication. The error correction analysis showed whether students were able to transfer the grammatical structures to texts with real context. As Ferris (2002:74) points out: "Error correction should not be seen as the means to eradicate all student errors but as the means to encourage gradual but consistent improvement in accuracy over time, acquisition and application of linguistic knowledge, and development of effective self-editing strategies."

From this point on, we will be concerned with error analysis, i.e., we will observe, analyse and classify students' errors. Gass and Selinker (2001:79) point out the main steps that need to be taken when doing error analysis: 1. Data collection; 2. Error identification; 3. Error classification; 4. Error quantification. We expected students who received error feedback via the computer program to improve their written accuracy over time because grammatical awareness and error feedback " $[. .$.$] can indeed promote$ L2 acquisition, at least for specific structures and for certain types of learners. In fact, instruction and 'negative evidence' might be essential for mastery of certain structures for adult and adolescent learners" (Schult, 1998:50).

The study is divided into two phases: in the first phase the program Markin was used to help students acquire autonomy in the error analysis of their own written work and aid the teacher in monitoring progress by making use of the accurate statistical information it provided. In the second phase, Markin was used in combination with Genre Theory, which shows students how to write and helps them to be aware of how knowledge is structured in different written genres.

\subsection{The first phase}

In both years there were sixty Spanish students in the fourth and final year of their English degree course. They wrote two essays: one in December at the end of the first term, and the other one in April at the end of the second term. Both were compulsory in order to obtain their final grade. The samples for the first and second year were a random selection of forty essays taken from each year, therefore in the first year the total number of writings analysed totalled forty essays.

Due to the number of students in each class and the amount of work to be monitored, a decision was made to implement CALL in the classroom to assist students in improving their writing and help teachers in the correction process. Firstly, it was necessary to take into consideration that the use of CALL implies a change in the teachers' role. As Pérez Gutiérrez and Pérez Torres (2005:576) highlight: "In fact, computers are a powerful tool which can replace the teacher's role of instructor in many occasions and help students become more autonomous [...]"

The use of CALL should facilitate some of the teacher's tasks while at the same time individualising the instruction (Cabero, 2001:322-324). For this reason we decided to use the program Markin during the first year of the study where our objectives were the following: students should get plenty of practice in writing, receive help and feedback during the writing process, and be more autonomous learners. 


\subsubsection{Use of the computer program Markin in the first year}

Initially, the most important functions of CALL in English Language IV were twofold: to facilitate the teacher's task of correcting the work of such a large number of students and to provide the students with a certain amount of autonomy in the process of error correction. However, there was also the need to compile information on these processes. As Drury (2004: 234) declares: "As teachers move into this medium of instruction, they not only need to learn how to use the new technology to create learning materials and experiences online but also to decide how, and to what extent, they will integrate these online materials with their current curriculum and assessment practices".

It was essential to monitor both processes, "namely to collect valid data that show what learners are really doing in language learning tasks" (Hsien-Chin, 2000:66). The need to have a reliable source of statistics that could be used to evaluate the learning process led us to the program Markin, a text correction computer program developed by Martin Holmes (1996-2002).

The program assesses not only quantitatively but also qualitatively. This was one of the key features of Markin which made it the perfect choice for this study. The errors were first recorded on an individual basis and then globally to permit interpretation of the results for both individual students and the group as a whole.

Markin is easy to use, compatible with other programs (Word, Notepad, etc.), adaptable to the teacher's needs (possibility to change correction code, etc), and interactive as it allows for extensive comments to be added to the correction process. It also has the advantage of keeping statistical records which can later be used to evaluate the correction process. The interface that the teachers worked with provided an ample array of grammar errors that went from the categories of spelling and punctuation to dangling modifiers and misuse of prepositions. All of these were errors that students in English Language IV should not make. We made sure that students understood the corrections provided by Markin so that they could benefit from the feedback. In general, L2 student writers value error feedback, i.e., they do not find it discouraging or demotivating. We agree with Ellis (1994:601) in that "error treatment constitutes an interactional event of considerable complexity". Figure 1 illustrates the interface of the program which can be adapted to the needs of the teacher.

After having given the students the placement test at the beginning of the first year, we identified the most problematic areas, which were the following: verb tense, subject/verb agreement, singular/plural error, verb form, article error, parallel construction problem, missing word or words, count/non-count error, sentence fragment, word order problem, wrong use of pronoun reference, wrong or misused preposition error and misplaced or dangling modifier. These errors were corrected and drilled at a sentence level and they were also adapted to the correction code for the Markin program.

The students were given a choice of topics and were told to write an essay. They then sent a word file which was uploaded onto the correction program and marked by the teacher. Afterwards, the students received an html file in which the errors were identified and the comments could be read. The errors were not corrected by the teacher but identified with one of the error tags from the program. The student then had to correct the errors using the material / knowledge acquired in the grammar correction classes. Following Ellis (1990:45), we consider errors significant in three different 


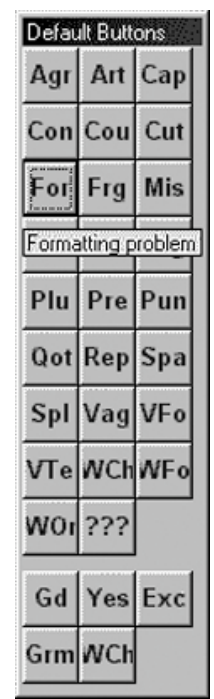

Fig 1. Correction code buttons.

ways: "[...] of value to the teacher - they indicated how far the learner had progressed towards the final goal. The other two concerned the researcher (errors provided evidence of how language is learned) and the learner (errors were used to test hypotheses)".

After the errors had been corrected, the program automatically tabulated the statistics which were part of the html document sent to the students. The type of error and the frequency of error were shown. These statistics were then tabulated for the group as a whole after the first and the second batch of essays in the first year.

Once the correction process of the eighty essays had been completed, the statistics tabulated for the group as a whole showed surprising results. Although the correction process and the monitoring of errors had been facilitated for the teacher, there was only a slight improvement in the students' grammar. Many basic errors still appeared in the second set of essays where there were still errors concerning verb tenses, prepositions, articles, etc. Figure 2 shows the type of general grammar errors made by the students.

A general overview of the essays as a whole showed that there were numerous

Table 1 Statistics for students

\begin{tabular}{|c|c|c|}
\hline Instances & & Description \\
\hline 1 & & Missing word or words \\
\hline 3 & & Wrong or misused preposition \\
\hline 2 & & Singular/plural error \\
\hline 2 & & Spelling \\
\hline 1 & & Poor word choice \\
\hline 1 & & Excellent! Well done. \\
\hline Negative total: & 11 & \\
\hline Positive total: & 1 & \\
\hline
\end{tabular}


problem areas in textuality. Although the students had in some ways begun to identify specific errors, it became necessary to emphasize the relationship between grammar and textuality to better the students' writing skills.

Subsequently, we decided to use the correction code to check the errors and difficulties in textuality. Through a careful reading process the following areas were found to be the most problematic.

Figure 3 shows the overall writing skills of the students in which it is evident that there were many problem areas. Out of the sample of forty essays, only ten were well structured, only half introduced the topic adequately and less than half gave appropriate examples.

The decision was made to continue the use of CALL as the Markin program had begun to serve a dual purpose: it was a reliable form of monitoring students' progress and an accurate means for gathering statistic concerning the types of errors committed. However, it was also decided that additional methods would be used to better the writing skills of the students. After analysing the results of the first year, both the program and Genre Theory were implemented in the second year, so that students could see models of good writing and analyse textual structure in depth, taking into consideration the cultural and social context of the texts. One of the main merits of using the Genre Theory in our teaching is that teachers and students concentrate on the context, on the writing situation, and a real audience is kept in mind in order to write an effective text following the patterns of the genre.

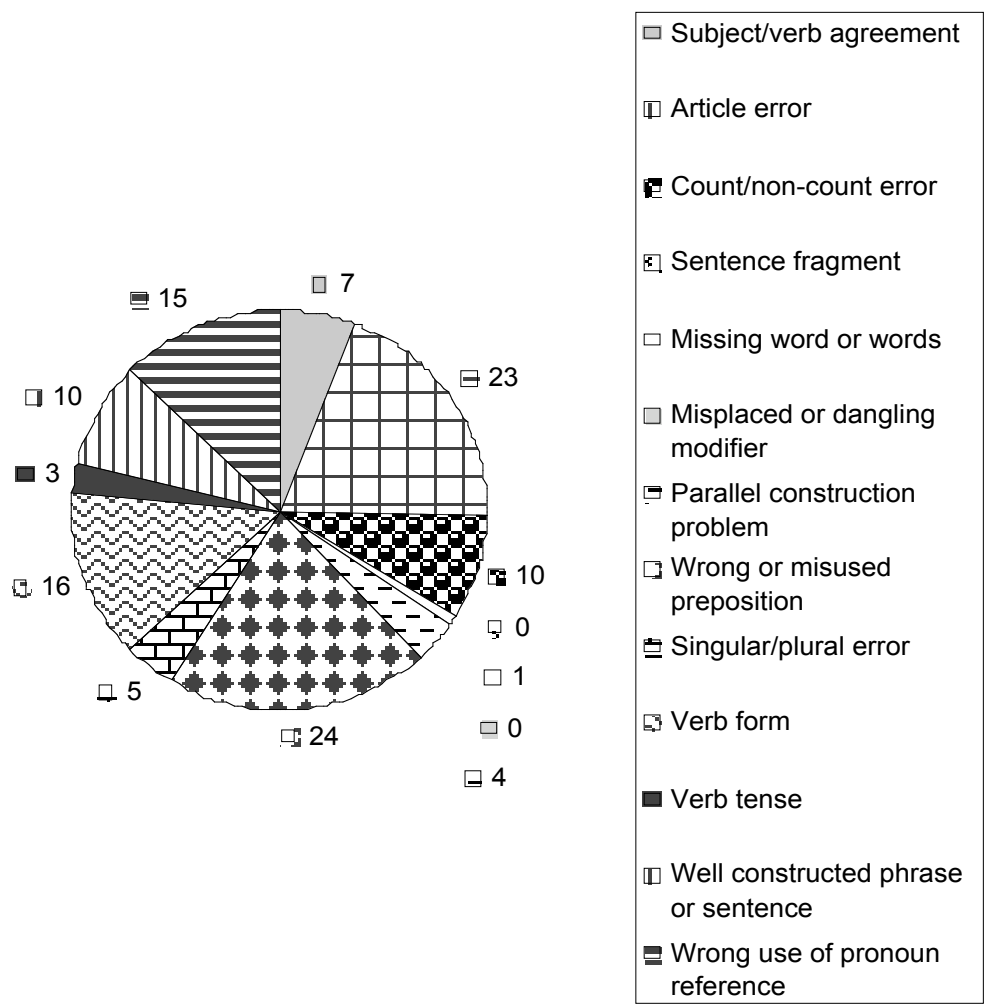

Fig 2. The results of the first year study in grammar errors. 

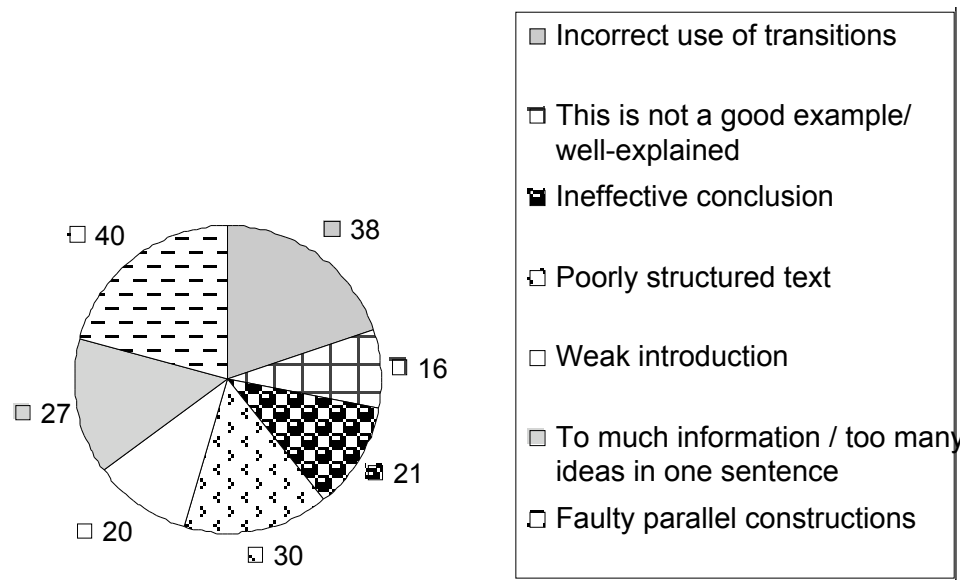

Fig 3. The results of the first year study in textuality errors.

\subsection{The second phase: Genre Theory as a framework}

The second phase of this study is characterized by a change in the methodology and in the theoretical framework. In the second year, we realized that the students needed models to follow and instead of working with sentence error correction, we worked with a selection of text types, as Genre Theory proposes. This is crucial for the learning process because once students understand the text as a whole, they will be able to adapt the text to different contexts and situations. We decided to continue using the computer program Markin not because it could assist us with the implementation of the Genre Theory but because it is a very useful tool for error analysis and provides accurate statistical records for research.

Texts that share the same purpose in the culture and have many of the same obligatory and optional features are called genres or text types. In this paper, we shall understand the genre as "a staged, goal-oriented, purposeful activity in which speakers engage as members of our culture" (Martin, 1984:25). In other words, genres are used to do things with language, to accomplish actions or facts inside a culture.

Butt el al. (2000:9) enumerate the following text types: recount, narrative, procedure, information report, explanation, exposition and discussion. As proponents of the genre approach, we highlight the importance of making genres or text types explicit so that students learn how to write them and how to organize knowledge and information depending on the text type. This way, students will be empowered to deal with various written genres and to use them in the appropriate context. As Drury (2004: 233) highlights, this approach "[...] engages students in an interactive teaching/learning cycle where they acquire knowledge, understanding, practice in and feedback on the target genres and apply this in producing their own texts for particular purposes".

Genre Theory highlights the importance of writing effective texts that contain ideas consistent with the cultural conventions in which the texts are written. In this manner, writing will result in coherent texts that fit their cultural settings. As Martínez Lirola (2006:149) points out: "This is essential so that students can see how members of a 
Table 2 Main difficulties in textuality

\begin{tabular}{|lll|}
\hline Poorly structured text $\quad$ Incorrect use of transitions & Weak introduction & Ineffective conclusion. \\
Faulty parallel constructions. & $\begin{array}{l}\text { Too much information } \\
\text { / too many ideas in one sentence. }\end{array}$ & $\begin{array}{l}\text { This is not a good example } \\
\text { / well explained. }\end{array}$ \\
\hline
\end{tabular}

culture use written texts as part of their social lives and they can conclude that the purpose of a genre determines its shape, i.e., its schematic structure".

By using the genre approach, teachers can highlight any linguistic aspect in the teaching and learning process, because this approach considers that all levels in language are interrelated, as Figure 4 shows.

As we can see in Figure 4, the content level of language has two levels: semantics and lexicogrammar. In the words of Butt et al. (2000:6): "More technically, we refer to systems of meaning as SEMANTICS ${ }^{1}$ and systems of wordings or signing as LEXICOGRAMMAR, which simply means words and the way they are arranged". The model of language presented in the previous figure shows that the study of words and grammar are part of a broader study of discourse.

As Bazerman and Prior (2004:2) point out: "To understand writing, we need to explore the practices that people engage in to produce texts as well as the ways that writing practices gain their meanings and functions as dynamic elements of specific cultural settings". Once students are confident in recognizing and producing text types, they can use them for different purposes taking into consideration their communicative purpose, the audience, the level of formality, etc. This is essential for students to conclude that the purpose of a genre determines its shape, i.e., its schematic structure. Consequently, students perceive the interconnectedness between the linguistic and the social, since people's use of language depends on the activities they want to carry out in their social lives.

This approach contrasts with the previous experiences of teaching writing in English Language IV in which students were asked to produce texts without being exposed to good models of written texts. Students were not taught the different genres or text types; the teaching of writing was focused on the formal aspects of the written text, which implied that the functional aspects were ignored; the idea of context and its relationship with the written text was neglected, and students were not taught that the linguistic characteristics of a text help readers to predict the context of it.

One of our main concerns is to improve students' writing by providing a context and selecting a theoretical framework in which students learn to write better or more easily. Students need to acquire control over the different kinds of texts that they need to express meaning or get different things done in a particular culture, and to be aware of how the grammar works. To teach students how written language draws on the resources of grammar, we helped them to understand: "(1) how the grammar of written language works, (2) how grammatical features cluster in particular text types, and (3) how grammatical knowledge relates to the skills of reading and writing" (De Sylva Joyce \&

1 Capital letters appear in the original text 


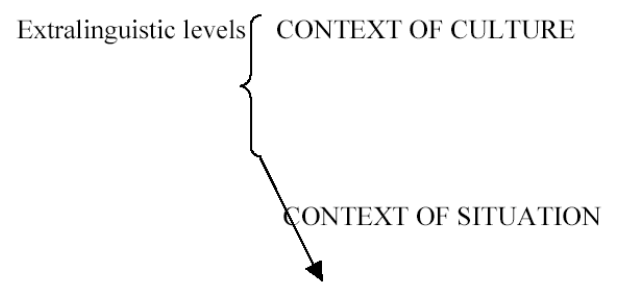

realized in

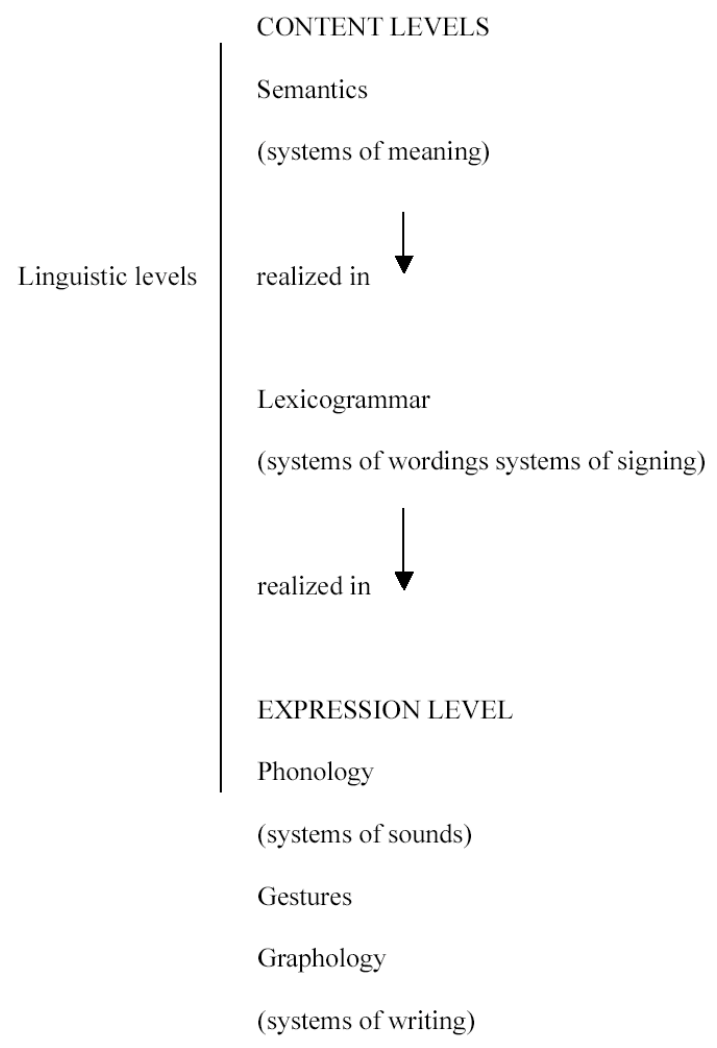

Fig 4. Levels of language (Butt et al., 2000:7).

Burns, 1999:118).

Once students were aware that the choice of vocabulary and grammatical patterns was not random, but clearly determined by the different purposes of the text types, we also taught students that beginnings, middles and ends have distinct functions in different text types. The shape of a text (its schematic structure) is determined by its purpose.

Let us look at one example of a common text type to illustrate this. This is an example of explanation (Droga \& Humphrey, 2003:7) that should be analysed by students so that they can identify the structure of the text and the main grammatical features. Following Genre Theory, exposing students to good texts and analysing them is crucial in order to 
help them to produce good texts:

- Social purpose: To explain scientifically how technological and natural phenomena come into being.

- Text structure: Why volcanic eruptions occur.

- Statement of phenomenon: Volcanic eruptions often occur at the boundaries of the colliding of plates. These plate boundaries are called subduction zones.

- Explanation sequence: When the two plates collide, one plate is forced underneath the other. Because the plate moves downwards, it heats up. The heating creates magma. As the heat and pressure continue to build up, the magma bursts through the crust. This results in hot lava and gases being released into the atmosphere along with rocks and smoke.

Key grammatical features (Droga \& Humphrey, 2003:142):

- Use of general, abstract, technical, non-human nouns

- Factual and classifying adjectivals to describe phenomenon

- Action verbs in the simple present to express events; relating verbs to do with cause/effect

- Use of time conjunctions, time/sequencing connectives and time adverbials (as themes) to sequence events in sequential explanations

- Use of causal conjunctions, causal connectives and causal adverbials (as themes in causal explanations

- Use of passive voice to foreground the object undergoing the process

- Use of nominalisation to summarise events and name abstract phenomena

Once students were aware of the main grammatical features in the text type under analysis, Markin was used to monitor the use of the previous grammatical features by the students in their writing. The correction code was adapted to the classification by Droga and Humphrey (2003:142) above. The results shown in Figure 5 demonstrate a
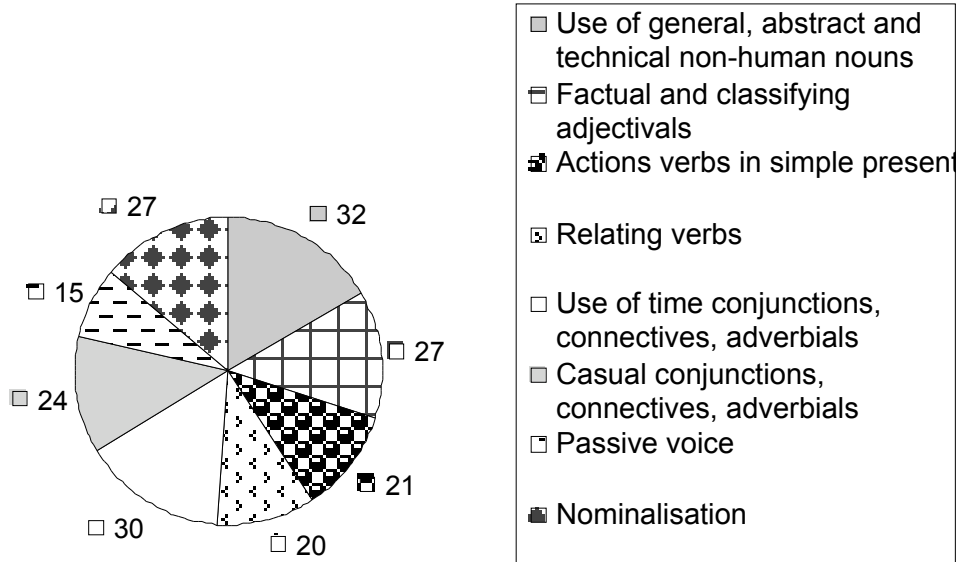

Fig 5. Key grammatical features in students' writings, following Droga and Humphrey (2003: 142). 
clear use of the grammatical features proposed by these authors on the part of the students who had assimilated the main grammatical features of this genre.

By using Genre Theory as a theoretical framework, we offered students good examples of different genres or text types, so that they could observe the different stages in the construction of the text. After that, students were asked to write their own texts following the stages found in the model.

Students were used to writing narratives and were aware that the social purpose of this text type was to entertain and instruct by dealing with unusual development of events, but they had never paid attention to the structure of this text type nor to the main grammatical features that characterize this genre.

The structure of narratives consists of four parts: the orientation describes the setting and introduces the narrator or characters; the complication introduces a sequence of events that are problematic for the characters; characters normally evaluate the events taking place; in the third place, we find the resolution, which deals with different attempts to solve the problem; finally, the coda is an optional stage that evaluates the whole incident and shows how the characters have been changed by the events.

In the second year, after having used Genre Theory the group of forty essays was marked using the correction code to positively identify the key grammatical features proposed by Droga and Humphrey (2003: 142). The errors were classified into grammar improvements and textuality improvements, in contrast to the first year. This was done to establish a comparison between both years in order to demonstrate any improvement in the students' writing.

Figure 6 shows a marked improvement in the last forty essays in well constructed

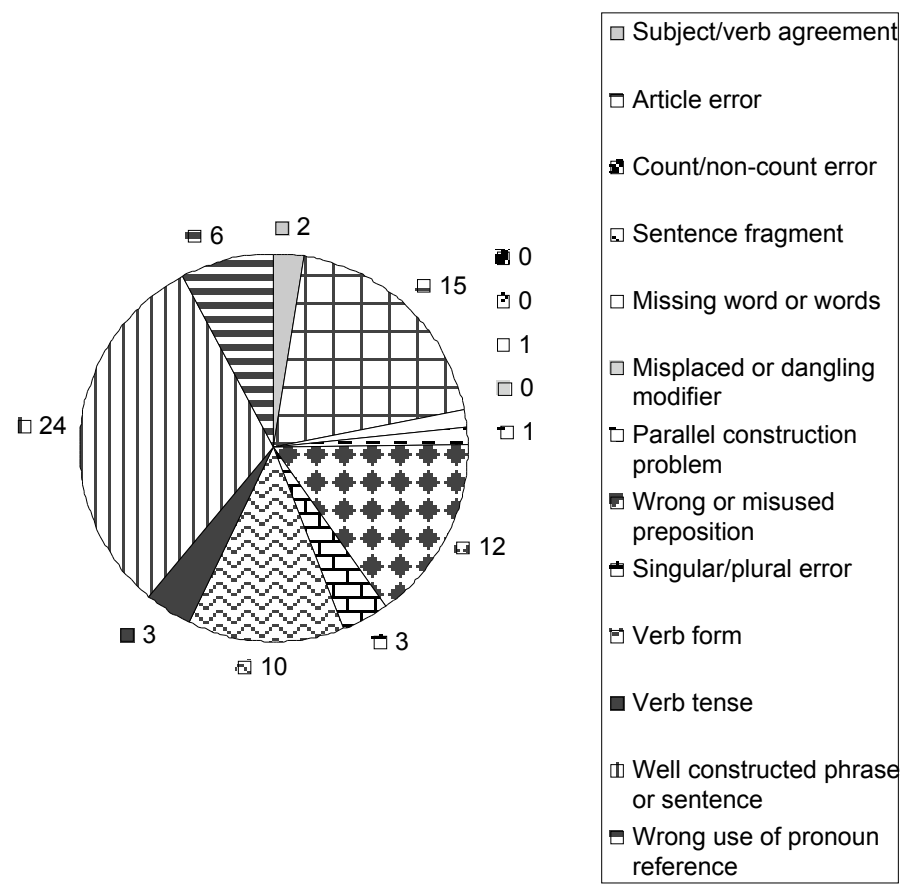

Fig 6. The results of the second year study in grammar errors 


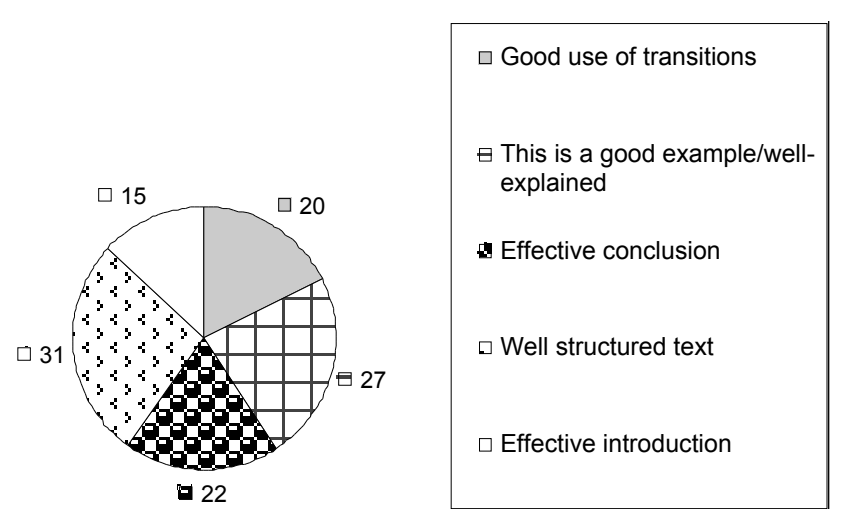

Fig 7. The results of the second year study in textuality improvements

phrases and sentence grammar in comparison with the first year study. There was also a substantial decrease in the number of common errors like the misuse of articles, incorrect verb forms and misused prepositions (these results can be compared with the results shown in Figure 2).

Figure 7 clearly demonstrates a marked improvement in the overall writing skills of the students. Texts, in general, were well structured, had strong beginnings and thought provoking endings. There was also an increased number of good illustrations and a much more frequent use of transitions.

\section{Conclusions}

The combination of CALL and Genre Theory helped students to improve their writing for several reasons:

In the first place, technology has a great influence in the process of teaching and learning second languages. The use of CALL has facilitated a shift from a teachercentred to a student-centred approach to learning. Additionally, the use of this computer program has increased learner autonomy since each student received the corrections to their own errors and personal suggestions for improving them. This was beneficial as the students were not afraid of correction but saw it as a positive element in the learning process. However, the focus on only the intersentential elements was not sufficient to improve their writing, as shown by the data collected.

The use of the computer software to annotate the students' texts facilitated the process of setting their grades and allowed the teacher to compare students' grades in a very o rganized and systematic way. Moreover, as previously mentioned, Markin was also selected because it assesses not only quantitatively but also qualitatively. The latter form of assessment was crucial in monitoring the students' progress in the application of Genre Theory to their writing.

In our view, using Markin to correct students' essays has offered us the following advantages: (1) a higher level of interaction between students and teacher; (2) an easy to use program compatible with other programs; (3) immediate access to students' work which can be kept for a long time, which is useful for research purposes; (4) 
individualization of the learning process; (5) an improvement in the correction process for the teacher; (6) an adaptable correction code to monitor improvements in students' written work.

Secondly, the use of Genre Theory in combination with CALL is an effective theoretical framework for teaching as it ensures that students become aware of the different genres or text types, which implies that students are aware of the social purpose, text structure and key grammatical features of each text type. Genre Theory enables students to write effective, coherent texts following the conventions that govern the structure and language of the different text types. Additionally, students are qualified to write with an understanding of the impact of language choices.

Moreover, Genre Theory focuses on the relationship between texts and the context in which those texts occur, and offers tools for the analysis of texts. Consequently, we can see an educational application of this discipline since it teaches students to produce written texts in social contexts depending on their social needs. A knowledge of Genre Theory makes students read with an understanding of what writers are trying to do with their language choices. At the same time, this approach makes students reflect on themselves as writers.

Genre Theory is a very suitable approach for the interpretation of 'text and context' and 'language learning and development'. We have applied Genre Theory to the analysis of texts in order to help students to write better or more easily, and we did this in the language class as this is the place where individuals can experiment with communication. By taking Genre Theory as a framework to analyse students' texts and by using CALL to monitor the errors and improvements, our aim was to pay attention to the importance of the organization of information at text level, and to see the text as a social product reflecting the social context in which it is written, thus highlighting the connection between form and meaning.

\section{References}

Bazerman, C. and Prior, P. (2004) Introduction. In: Bazerman, C. and Prior, P. (eds.) What Writing Does and How it Does it. An Introduction to Analyzing Texts and Textual Practices. New Jersey: Lawrence Erlbaum Associates, 1-10.

Butt, D., Fahey, R., Spinks, S and Yallop, C. (2000) Using Functional Grammar. An Explorer's Guide. Second edition. Sydney: NCELTR.

Cabero, J. (2001) Tecnología educativa. Diseño y utilización de medios en la enseñanza. Barcelona: Paidós.

Cabellos, M.R., Díaz, M. and Halbach, A. (2002) The Contribution of Thematic Distribution to the Cohesion of Texts: Thematic Progression in Writings of EFL Students. In: Sierra Ayala, L. and Morra de la Peña, A.M. (eds.) Research in Academic English: Communicative Skills and Strategies in the University Context. Alcalá de Henares: Servicio de Publicaciones de la Universidad, 79-105.

De Sylva Joyce, H. and Burns, A. (1999) Focus on Grammar. Sydney: NCELTR.

Díez, M., Halbach, A. and Rivas, C. (2002) Student Difficulties with Writing: A Look at Cohesion. In: Sierra Ayala, L. and Morra de la Peña, A.M. (eds.) Research in Academic English: Communicative Skills and Strategies in the University Context. Alcalá de Henares: Servicio de Publicaciones de la Universidad, 69-78.

Droga, L. and Humphrey, S. (2003) Grammar and Meaning. An Introduction for Primary 
Teachers. Berry NSW: Ta rget Texts.

Drury, H. (2004) Teaching academic writing on screen: a search for best practice. In: Ellis, R. and Ravelli, J.L. (eds.) Analysing Academic Writing. Contextualised Frameworks. London: Continuum, 233-253.

Ellis, R. (1990) Instructed Second Language Acquisition. Learning in the Classroom. Oxford: Blackwell.

Ellis, R. (1994) The Study of Second Language Acquisition. Oxford: Oxford University Press.

Feng, C., Ogata, H. and Yano, Y. (2000) Mark-up based writing error analysis model in an on-line classroom. CALL, 13 (1): 79-97.

Fernández Carballo-Calero, M.V. (2001) The EFL teacher and the introduction of multimedia in the classroom. CALL 14 (1): 3-14.

Ferris, D. R. (2002) Treatment of Error in Second Language Student Writing. Michigan: The University of Michigan Press.

Gass, S.M. and Selinker, L. (2001) Second Language Acquisition. An Introductory Course. Mahwah: Lawrence Erlbaum Associates.

Halliday, M.A.K. (1978) Language as Social Semiotic: The Social Interpretation of Language and Meaning. London: Edward Arnold.

Halliday, M.A.K (1994) An Introduction to Functional Grammar. Second edition. London: Arnold.

Halliday, M.A.K and Hasan, R. (1976) Cohesion in English. London: Longman.

Hammond, J. and Derewianka, B. (2001) Genre. In: Carter, R. and Nunan, D. (eds.) The Cambridge Guide to Teaching English to Speakers of Other Languages. Cambridge: Cambridge University Press,186-193.

Hewings, M. (2005) Advanced Grammar in Use. Cambridge: Cambridge University Press.

Hogan-Brun, G. and Whittle, R. (1998) The potential of multi-media for foreign language learning: a critical evaluation. Computers and the Humanities, 31: 451-457.

Holmes, M. (1996-2002) "Markin version 3.0." (Software program) Shareware Windows Program for Marking Student Essays". Creative Technology (Microdesign) Ltd. Uttoxeter. http://www.cict.co.uk/markin/

Hsien-Chin, L. (2000) Assessing Learner Strategies Using Computers: New Insights and Limitations. CALL, 13 (1): 65-78.

Krashen, S. (1985) The Input Hypothesis. London: Longman.

Martin, J.R. (1997) Analysing genre: functional parameters. In: Christie, F. and Martin J.R. (eds.) Genres and Institutions: Social Processes in the Workplace and School. London: Cassell, 3-39.

Martin, J. R. (1984) Language, Register, and Genre. In: Christie, F. (ed.) Children Writing: Reader. Geelong, Vic: Deakin University Press, 21-29.

Martínez Lirola, M. (2006) The importance of teaching Systemic Functional Linguistics and Text Linguistics to improve writing in Bilingual Education Programs in the USA. Porta Linguarum. Revista Internacional de Didáctica de las Lenguas Extranjeras, 5: 139-150.

Pérez Gutiérrez, M and Pérez Torres, I. (2005) Audio-visual resources and new technologies in ELT. In: Madrid, D., Mclaren, N. and Bueno, A. (eds.) TEFL in Secondary Education. Granada: Universidad de Granada, 545-578.

Schult, R.A. (1998) Focus on form in the foreign language classroom: students' and teachers's view of error correction and the role of grammar. In: Alcón Soler, E. and Codina Espurz, V. (eds.), Current Issues in English Language methodology. Castelló de la Plana: Universitat Jaume I, 49-76. 